\title{
A mechanism for fire retardancy realized by a combination of biofillers and ammonium polyphosphate in various polymer systems
}

\author{
Koki Matsumoto $\mathbb{D} \cdot$ Tatsuya Tanaka $\cdot$ Masahiro Sasada $\cdot$ Noriyuki Sano $•$ \\ Kenta Masuyama
}

Received: 30 June 2020/Revised: 22 January 2021 / Accepted: 3 February 2021 / Published online: 22 February 2021

(C) The Author(s) 2021

\begin{abstract}
This study focused on realizing fire retardancy for polymer composites by using a cellulosic biofiller and ammonium polyphosphate (APP). The motivation of this study was based on revealing the mechanism of the synergetic effect of a cellulosic biofiller and APP and determining the parameters required for achieving a V-0 rating in UL94 standard regardless of the kind of polymer system used. As for the polymer matrix, polypropylene and polylactic acid were used. The flammability, burning behavior and thermal decomposition behavior of the composites were investigated through a burning test according to the UL-94 standard, cone calorimetric test and thermogravimetric analysis. As a result, the incorporation of a high amount of cellulose enabled a V-0 rating to be achieved with only a small amount of APP despite
\end{abstract}

\footnotetext{
K. Matsumoto $(\square)$

Department of Mechanical Engineering, Kanagawa

University, Yokohama, Kanagawa, Japan

e-mail: koki-matsumoto@kanagawa-u.ac.jp

T. Tanaka

Department of Mechanical Engineering and Science, Doshisha University, Kyotanabe, Kyoto, Japan

M. Sasada

Department of Mechanical and System Engineering, Doshisha University, Kyotanabe, Kyoto, Japan

N. Sano · K. Masuyama

Department of Mechanical Engineering, Doshisha

University, Kyotanabe, Kyoto, Japan
}

the variation of the optimum cellulose loading between the matrix polymers. Through analysis, the results indicated that APP decreased the dehydration temperature of cellulose. Furthermore, APP promoted the generation of enough water as a nonflammable gas and formed enough char until the degradation of the polymer matrix was complete. The conditions required to achieve the $\mathrm{V}-0$ rating were suggested against composites incorporating APP and biofillers. Furthermore, the suggested conditions were validated by using polyoxymethylene as a highly flammable polymer.

Keywords Fire retardancy $\cdot$ Cellulose $\cdot$ Ammonium polyphosphate $\cdot$ Dehydration $\cdot$ Char formation

\section{Introduction}

Application of polymer composites for electronic device parts, construction and automobiles requires strict fire retardancy for protection from fire hazards. The use of fire retardant is a common way to provide fire retardancy for polymer composites, and fire retardancy is characterized according to UL 94 standard (2013). Due to environmental concerns, non-halogenated fire retardants including aluminum hydroxides, magnesium hydrate, intumescent fire retardants, phosphorus-containing fire retardants and biobased fire retardants have received great attention 
(Liao et al. 2015; Costes et al. 2016a). However, a high amount of fire retardant (more than $30 \mathrm{wt} \%$ ) is necessary for achieving excellent fire retardancy. Consequently, this leads to increased material cost and deterioration of mechanical properties (Arao et al. 2014; Fox et al. 2014).

Biofillers, such as lignocellulosic- and cellulosicmaterials, are relatively inexpensive materials and have great potential to reduce environmental loading and to improve the mechanical properties of polymers. Incorporation of biofillers into petroleum-derived polymers increases the biomass ratio. Furthermore, biodegradable polymers, such as polylactic acid (PLA) and polybutylene succinate (PBS), have been focused on as ecofriendly materials. However, the high flammability of biocomposites limits their applicability, and improvement of fire retardancy remains challenging (Matkó et al. 2005). The general burning pattern of a polymer can be explained by the following stages (Ahmed et al. 2018): After forced ignition against a polymer, (1) pyrolysis by inducing further heat, (2) release of inflammable gas, (3) combustion by mixing of the released gas with oxygen, and (4) release of further heat by combustion process occurs in turn. This cycle continues until consumption of the material is complete. Therefore, this cycle should be stopped for improving the fire retardancy of polymer composites.

As a strategy for stopping this cycle by using a fire retardant, there are two main mechanisms in the gas phase involving the use of a nonflammable gas and a condensed phase formed by an insulation char layer (Castrovinci and Camino 2007; Bourbigot and Fontaine 2010). Especially for wood-plastic composites (WPC), the use of ammonium polyphosphate (APP) containing a high level of phosphorous and nitrogen is an effective solution ( $\mathrm{Li}$ and $\mathrm{He}$ 2004; Stark et al. 2010; Arao et al. 2014; Jiang et al. 2018). Li and He (2004) showed that APP was more effective for increasing the limited oxygen index (LOI) of lowdensity polyethylene (LDPE)-wood fiber composites. Stark et al. (2010) also revealed that the addition of APP improved the LOI and reduced the heat release rate (HRR) in a cone calorimeter against wood flour (WF)-PE composites. In our previous work, Arao et al. (2014) found that a combination of APP and WF showed good results for fire retardancy compared to various fire retardants. The amount of APP could be reduced to $10 \mathrm{wt} \%$ by adding $50 \mathrm{wt} \%$ of WF into polypropylene (PP) for achieving V-0 class in UL94. APP was found to interact with the carbonaceous structure of wood during combustion, which aided the formation of char layer. The synergetic effect of the char layer and nonflammable gas improved the fire retardancy of WPC. Jiang et al. (2018) introduced nano silica into a system of APP filled in WPC by in situ polymerization, which led to an increased LOI and decreased peak in the HRR (pHRR).

From a different perspective, cellulose, which is major component of biofillers, shows effective performance for realizing fire retardancy for a polymer composite by a synergetic effect with APP. The cellulose-based fibers can be suitable for use as fire retardant with phosphorus-based fire retardants owing to the presence of hydroxyl groups (Salmeia et al. 2016). During the thermal decomposition process, the phosphorus-based fire retardant can dehydrate cellulose and enhance the formation of the char layer (Salmeia et al. 2016; Fox et al. 2014). Therefore, the state-of-the-art concept for improving fire retardancy involves the modification of cellulose (Fox et al. 2014; Costes et al. 2016b; Guo et al. 2017; Bajwa et al. 2019). The use of polyhedral oligomeric silsesquioxane (POSS)-modified cellulose (Fox et al. 2014), chemical grafting of phosphorus onto a microcrystalline cellulose surface (Costes et al. 2016a, b), introducing resorcinol bis(diphenyl phosphate) (RDP) coated cellulose (Guo et al. 2017), and functionalization of cellulose nanocrystals (CNC) with nanosized zinc oxide ( $\mathrm{ZnO})$ (Bajwa et al. 2019) are all effective solutions.

From an industrial point of view, minimizing the amount of fire retardant and increasing the biofiller content are both important for saving material cost and improving mechanical properties. Thus, the motivation of this study is to reveal the synergetic effect of cellulose and APP against fire retardancy and its underlying mechanism regardless of the polymeric system present in the composites. In this study, PP (a kind of polyolefin) and PLA (a biodegradable polymer) is chose as a polymer matrix. The LOI for PP and PLA is $18 \%$ (Kozłowski and Władyka-Przybylak 2008), 19-21\% (Liao et al. 2015; Bourbigot and Fontaine 2010; Chow et al. 2018), respectively. Since an air atmosphere is composed of approximately $21 \%$ oxygen, polymers with a LOI of less than 21 signify flammability. Hence, PP and PLA are classified as high- and low-flammability in this paper. As for the 
biofiller, cellulose particles (CP) were incorporated with APP into each polymer.

In this study, to determine the critical conditions for achieving a V-0 rating in UL 94, the influence of CP loading and difference in polymer matrix were investigated. We conducted a burning test according to UL 94. Thermogravimetric analysis (TGA), cone calorimetric analysis and measurement of the thickness of char layer were carried out for interpreting the results of the burning test. Through these tests, we proposed the conditions for satisfying the V-0 class in UL 94 in a quantitative way.

\section{Materials and preparation of composites}

\section{Materials}

As a matrix of polymer composites, the homopolymer type of PP (type J108M) was purchased from Prime Polymer Co., Ltd., Tokyo, Japan. This polymer has a melt flow rate of $45 \mathrm{~g} / 10 \mathrm{~min}\left(230{ }^{\circ} \mathrm{C}, 2.16 \mathrm{~kg}\right)$ as typical for an injection molding grade material. To improve the compatibility of PP and cellulose, 3.3 $\mathrm{wt} \%$ of maleic anhydride grafted polypropylene (MAPP) (UMEX1001, Sanyo Chemical Industries Co., Ltd., Kyoto, Japan) was added to PP composites. The value was preliminary optimized against $50 \mathrm{wt} \%$ of CPs in terms of tensile strength. PLA (REVODE110) was supplied from Zhejiang Hisun Biomaterials Co., Ltd., Taizhou, Zhejiang, China. This polymer has a melt index of $2-10 \mathrm{~g} / 10 \mathrm{~min}\left(190{ }^{\circ} \mathrm{C}\right.$, $2.16 \mathrm{~kg}$ ), glass transition temperature of $59-62{ }^{\circ} \mathrm{C}$, and melting temperature of $155-160{ }^{\circ} \mathrm{C}$ according to the datasheet provided by the supplier.

As a biofiller, CPs (W100-GK) were purchased from Nippon Paper Industries Co., Ltd., Tokyo, Japan. The CPs had a mean particle size of approximately 37 $\mu \mathrm{m}$. As a halogen-free fire retardant, APP (Taien K) was purchased from Taihei Chemical Industrial Co., Ltd., Osaka, Japan. The phosphorus and nitrogen content in APP were approximately $30 \%$ and $16 \%$, respectively. The amount of APP was held constant at $10 \mathrm{wt} \%$ for PP composites and PLA composites according to our previous study (Arao et al. 2014).
Compounding

All the composites were prepared by melt mixing through a co-rotating twin-screw extruder (ZSK 18 MEGAlab, Coperion GmbH, Stuttgart, Germany) on a laboratory scale. The screw diameter was $18 \mathrm{~mm}$ and the length to diameter ratio (L/D) was 40 . The screw configurations for the twin-screw extruder differed between the PP composites and PLA composites. Each screw configuration is shown in Fig. 1a, b. In the case of the PP composites, all materials (i.e., PP granules, MAPP granules, CP and APP) were fed into a main hopper through a volumetric feeder. The temperature profile of the barrel was set as $170{ }^{\circ} \mathrm{C} / 170{ }^{\circ} \mathrm{C} / 140{ }^{\circ} \mathrm{C} /$ $140{ }^{\circ} \mathrm{C} / 140{ }^{\circ} \mathrm{C} / 140{ }^{\circ} \mathrm{C} / 175{ }^{\circ} \mathrm{C}$ from the inlet zone to die head. The rotation speed was $150 \mathrm{~min}^{-1}$, and the throughput was $1.0 \mathrm{~kg} / \mathrm{h}$.

In case of the PLA composites, the compounding process was divided into two steps due to the concern of hydrolytic degradation of PLA and carbonization of APP and CP. Initially, PLA granules and CP were fed into the main hopper and compounded at a screw speed of $150 \mathrm{~min}^{-1}$ and throughput of $1.0 \mathrm{~kg} / \mathrm{h}$. The temperature profile of the barrel was set as $180{ }^{\circ} \mathrm{C} /$ $175^{\circ} \mathrm{C} / 175^{\circ} \mathrm{C} / 170{ }^{\circ} \mathrm{C} / 170{ }^{\circ} \mathrm{C} / 165^{\circ} \mathrm{C} / 165{ }^{\circ} \mathrm{C}$. The compounds were obtained as masterbatch granules in the first process. Subsequently, the masterbatch granules and APP were compounded at the same screw speed and throughput used for the first process, and then the final compounds were obtained. The temperature profile of the barrel was set as $165{ }^{\circ} \mathrm{C} / 165^{\circ} \mathrm{C} /$ $140{ }^{\circ} \mathrm{C} / 140{ }^{\circ} \mathrm{C} / 140{ }^{\circ} \mathrm{C} / 140{ }^{\circ} \mathrm{C} / 180{ }^{\circ} \mathrm{C}$. Before compounding, PLA was dried in a vacuum oven for $3 \mathrm{~h}$ at $90{ }^{\circ} \mathrm{C}$. PP, CP and APP were dried in an oven for $24 \mathrm{~h}$ at $80{ }^{\circ} \mathrm{C}$. All formulations are listed in Table 1 .

Injection molding

By using the compounded granules through twinscrew extrusion, dumbbell specimens (type 1A, ISO 527) were molded through use of an injection molding machine (PLASTER ET-40V, TOYO MACHINERY \& METAL Co., Ltd., Akashi, Hyogo, Japan) with a clamping force of 40 tons. As for the molding conditions, the cylinder temperature was set at $175^{\circ} \mathrm{C}$ and $165^{\circ} \mathrm{C}$ for PP and PLA, respectively. The obtained specimens were cut for (a) flammability test for the UL 94 standard and (b) measurement of the thickness of the char layer, as shown in Fig. 2. The 
(a)

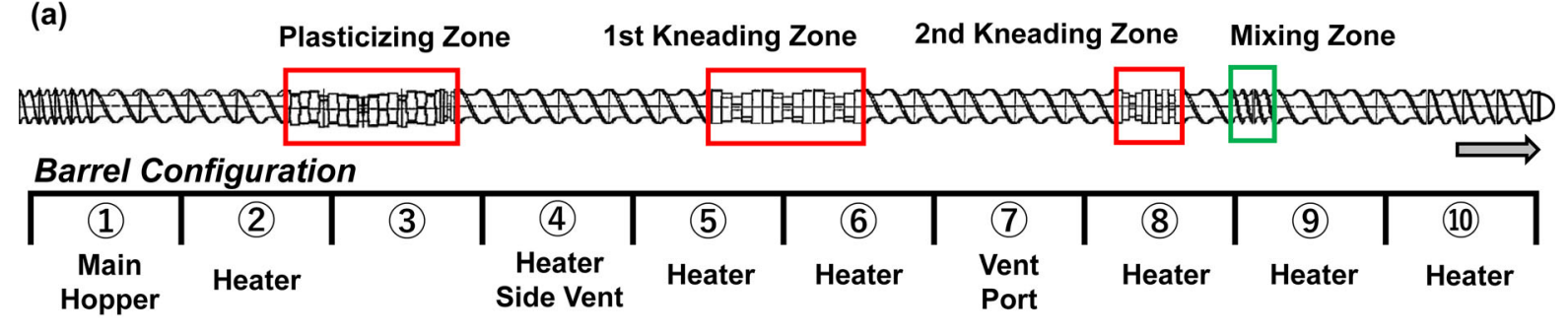

(b)

Plasticizing Zone

Conveying Zone

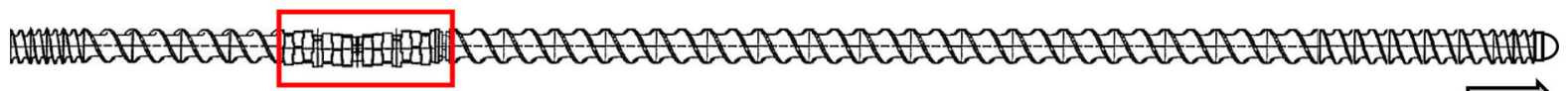

Barrel Configuration

\begin{tabular}{|c|c|c|c|c|c|c|c|c|c|}
\hline (1) & (2) & (3) & (4) & (5) & (6) & (7) & (8) & (9) & (10) \\
\hline $\begin{array}{l}\text { Main } \\
\text { Hopper }\end{array}$ & Heater & & $\begin{array}{c}\text { Heater } \\
\text { Side Vent }\end{array}$ & Heater & Heater & $\begin{array}{l}\text { Vent } \\
\text { Port }\end{array}$ & Heater & Heater & Heater \\
\hline
\end{tabular}

Fig. 1 Screw and barrel configurations for $\mathbf{a}$ PP-based composites and $\mathbf{b}$ PLA-based composites

Table 1 All formulations and abbreviations used for the prepared composites

\begin{tabular}{llllllllc}
\hline Samples & PP $(\mathrm{wt} \%)$ & MAPP $(\mathrm{wt} \%)$ & $\mathrm{CP}(\mathrm{wt} \%)$ & APP $(\mathrm{wt} \%)$ & Samples & PLA $(\mathrm{wt} \%)$ & CP $(\mathrm{wt} \%)$ & APP $(\mathrm{wt} \%)$ \\
\hline PP-0 & 100 & 0 & 0 & 0 & PLA-0 & 100 & 0 & 0 \\
PP-1 & 86.7 & 3.3 & 10 & 0 & PLA-1 & 90 & 10 & 0 \\
PP-2 & 66.7 & 3.3 & 30 & 0 & PLA-2 & 70 & 30 & 0 \\
PP-3 & 46.7 & 3.3 & 50 & 0 & PLA-3 & 60 & 40 & 0 \\
PP-4 & 86.7 & 3.3 & 0 & 10 & PLA-4 & 90 & 0 & 10 \\
PP-5 & 76.7 & 3.3 & 10 & 10 & PLA-5 & 80 & 10 & 10 \\
PP-6 & 56.7 & 3.3 & 30 & 10 & PLA-6 & 60 & 30 & 10 \\
PP-7 & 36.7 & 3.3 & 50 & 10 & PLA-7 & 50 & 40 & 10 \\
\hline
\end{tabular}

dimensions are also presented in the same figure. Additionally, plate specimens $(50 \mathrm{~mm} \times 50 \mathrm{~mm} \times 3.3$ $\mathrm{mm}$ ) were also molded for the cone calorimetry test. The compounded pellets were dried in an oven for 24 hours at $80{ }^{\circ} \mathrm{C}$ before injection molding.

\section{Evaluation methods for the flammability}

Flammability test

A flammability test was conducted by using the prepared specimens shown in Fig. 2a according to the UL 94 standard (2013). All samples were dried in an oven for $24 \mathrm{~h}$ at $80{ }^{\circ} \mathrm{C}$. For evaluating the flammability of the composites, a horizontal burning test and vertical burning test was conducted in this order. In the horizontal burning test, two lines were marked onto the samples in the direction perpendicular to the longitudinal axis at $20 \mathrm{~mm}$ and $80 \mathrm{~mm}$ from the end that was to be ignited. The samples were clamped at the opposite side of the ignition position, with the longitudinal axis horizontal and transverse axis inclined at $45^{\circ}$. A blue flame that was $20 \mathrm{~mm}$ high was applied to the lowest edge of the samples at a distance of $10 \mathrm{~mm}$ and angle of $30^{\circ}$ to the vertical for $30 \mathrm{~s}$. The time was recorded for the combustion front to travel from the $20 \mathrm{~mm}$ mark up to the $80 \mathrm{~mm}$ mark for calculation of the burning rate in $\mathrm{mm} / \mathrm{min}$. If the burning rate is less than $40 \mathrm{~mm} / \mathrm{min}$ in case of a 
Fig. 2 Schematic view of the test specimens for a flammability test and b measurement of the thickness of the char layer
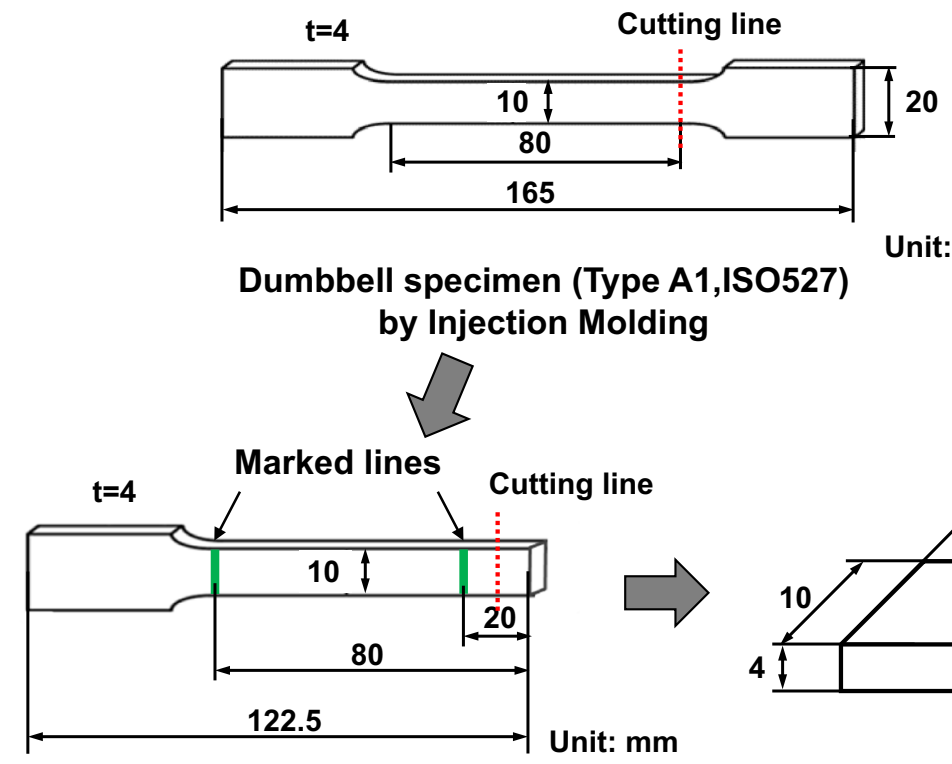

(a) Specimen for flammability test
in UL 94

(b) Specimen for measuring thickness of char layer thickness of $4 \mathrm{~mm}$, the flammability rating can be expressed as HB. The tests were conducted for 5 times for each specimen.

For the samples that had a satisfactory HB rating, an additional vertical burning test was conducted for judging the achievement of a V-0 rating. The sample was clamped with the longitudinal axis vertical. A blue flame with a height of $20 \mathrm{~mm}$ was supplied to the middle point of the bottom edge at a distance of $10 \mathrm{~mm}$ for $10 \mathrm{~s}$, and the afterflame time $\left(\mathrm{t}_{1}\right)$ was measured. In case the combustion stopped, the sample was ignited again for $10 \mathrm{~s}$ and the afterflame time $\left(\mathrm{t}_{2}\right)$ and afterglow time $\left(\mathrm{t}_{3}\right)$ was recorded again. The V-0 class should satisfy all the following conditions: (a) $t_{1}$ or $t_{2}$ is less than $10 \mathrm{~s}$, (b) total time of $t_{1}$ plus $t_{2}$ for the 5 samples is less than $50 \mathrm{~s}$, (c) total time of $t_{2}$ plus $_{3}$ is less than $30 \mathrm{~s}$, (d) afterflame or afterglow does not reach the holding clamp and (e) cotton does not ignite by flaming particles or drippings. This test was also conducted for 5 times for each specimen.

Cone calorimetry test

Cone calorimetry was performed using a Cone Calorimeter III C3 (Toyo Seiki Seisaku-sho, Ltd., Tokyo, Japan). Through the cone calorimetry tests, HRR was measured for the molded plate samples. The
pHRR and total heat release (THR) was also determined from the results. Samples wrapped in aluminum foil were placed with a horizontal orientation above a conical radiant electric heater at a distance of $25 \mathrm{~mm}$. A heater temperature of $734.5^{\circ} \mathrm{C}$ and an external heat flux of $50 \mathrm{~kW} / \mathrm{m}^{2}$ were applied.

Measurement of the char layer thickness

The rectangular samples in Fig. 2b were burned enforcedly for observation of the growing thickness of the char layer against elapsed time. The burning time was varied as 10 s, $20 \mathrm{~s}$ and $30 \mathrm{~s}$, and the samples were quenched rapidly in water after each time elapsed. The quenched samples were dried for $24 \mathrm{~h}$ at $80{ }^{\circ} \mathrm{C}$. Afterward, the samples were embedded into a thermoset plastic, and the centerline of the samples was cut along a longitudinal direction. The 12 samples were prepared for each formulation. The thickness of the char layer at the cross-section was measured for 10 points against each samples (totally 120 points) by optical microscopy.

TGA test

The thermal decomposition behavior was measured by a TGA apparatus (DTG-50H, Shimadzu Co., Kyoto, 
Japan) under air atmosphere. A sample with a weight of $10-11 \mathrm{mg}$ was cut from injected specimens. The temperature was increased from room temperature to $600{ }^{\circ} \mathrm{C}$ under a heating rate of $10{ }^{\circ} \mathrm{C} / \mathrm{min}$. The weight loss was measured while increasing the temperature.

\section{Results and discussion}

Flammability and combustion behavior

The results obtained from the horizontal burning test and vertical burning test according to UL 94 against PP composites and PLA composites are shown in Table 2. The term self-extinguish denotes extinguishment of combustion after forced ignition against the horizontal burning test. The HRR curve for the cone calorimetry test is depicted in Fig. 3a for PP composites and Fig. $3 \mathrm{~b}$ for PLA composites. From these curves, the value of the pHRR, average HRR and THR were calculated and summarized in Table 3.

\section{Flammability properties of the neat polymers}

In the horizontal burning test, neat PP (PP-0) and PLA (PLA-0) did not show a self-extinguishing property. The average burning rate of neat $\mathrm{PP}$ is slightly higher than that of neat PLA, and the pHRR, average HRR and THR for the neat PP is approximately 2 times higher than that for neat PLA. The reason why PP has high flammability is that PP consists of carbon and hydrogen (Hanna et al. 2018). Furthermore, the calorific value of PP (43 MJ/kg) is higher than that of PLA (18 MJ/kg) (Castro-Aguirre et al. 2016) and
PP has a smaller LOI value than PLA. The calorific value refers to the production of heat per unit mass during combustion. Therefore, PLA has a lower flammability than PP.

\section{Effect of CP addition}

In case of only CP addition without APP, both PP (PP1 to PP-3) and PLA (PLA-1 to PLA-3) composites did not show a self-extinguishing property in the horizontal burning test and $\mathrm{V}-0$ rating in the vertical burning test. The burning rate of both composites was increased by adding $\mathrm{CP}$. Thermal conductivity plays an important role for the burning rate. The thermal conductivity of PP, PLA and cellulose is $0.26 \mathrm{Wm}^{-1}$ $\mathrm{K}^{-1}$ (Seefeldt 2012), 0.22 $\mathrm{Wm}^{-1} \mathrm{~K}^{-1}$ (Botlhoko et al. 2017), $0.04 \mathrm{Wm}^{-1} \mathrm{~K}^{-1}$ (Hurtado et al. 2016), respectively. A high thermal conductivity leads to a reduced local temperature, which, thus, reduces the burning rate (Seefeldt 2012). CP addition may reduce the thermal conductivity of both composites, and, therefore, lead to an increased burning rate.

However, the pHRR for both composites was significantly decreased compared with the neat matrices. Such a reduction in the pHRR has also been reported for the addition of wood flour due to lignocellulosic materials, which have a low HRR (Stark et al. 2010; Arao et al. 2014; Jiang et al. 2018). The dehydration reaction of cellulose leads to the production of water and formation of char, which, thus, reduce the amount of flammable gases (Kandola et al. 1996). Thus, endothermic reaction by the released water and protection by the char layer may enable the reduction in the HRR. However, increasing

Table 2 Burning rate and flame classification for PP-based composites and PLA-based composites

\begin{tabular}{llllll}
\hline Samples & $\begin{array}{l}\text { Average burning rate (mm/ } \\
\text { min) }\end{array}$ & $\begin{array}{l}\text { Class based on } \\
\text { UL94 }\end{array}$ & Samples & $\begin{array}{l}\text { Average burning rate (mm/ } \\
\text { min) }\end{array}$ & $\begin{array}{l}\text { Class based on } \\
\text { UL94 }\end{array}$ \\
\hline PP-0 & 24.3 & HB & PLA-0 & 23.0 & HB \\
PP-1 & 27.3 & HB & PLA-1 & 25.3 & HB \\
PP-2 & 29.1 & HB & PLA-2 & 28.7 & HB \\
PP-3 & 27.9 & HB & PLA-3 & 25.0 & HB \\
PP-4 & 21.8 & HB & PLA-4 & Self-extinguish & HB \\
PP-5 & 22.5 & HB & PLA-5 & Self-extinguish & HB \\
PP-6 & 14.5 & HB & PLA-6 & Self-extinguish & V-0 \\
PP-7 & Self-extinguish & V-0 & PLA-7 & Self-extinguish & V-0 \\
\hline
\end{tabular}



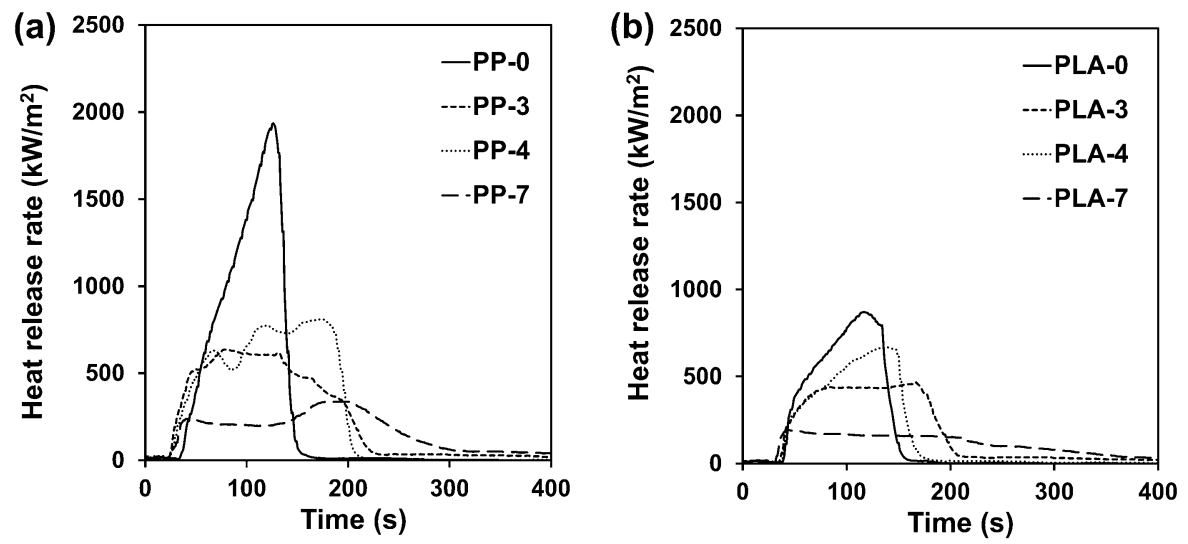

Fig. 3 Heat release rate curves for a PP-based composites and b PLA-based composites

Table 3 Peak of the heat release rate (pHRR), average HRR and total heat release rate (THR) for PP-based composites and PLAbased composites

\begin{tabular}{llllllll}
\hline Samples & $\begin{array}{l}\mathrm{pHRR}(\mathrm{kW} / \\
\left.\mathrm{m}^{2}\right)\end{array}$ & $\begin{array}{l}\text { average HRR }(\mathrm{kW} / \\
\left.\mathrm{m}^{2}\right)\end{array}$ & $\begin{array}{l}\text { THR }(\mathrm{MJ} / \\
\left.\mathrm{m}^{2}\right)\end{array}$ & Samples & $\begin{array}{l}\mathrm{pHRR}(\mathrm{kW} / \\
\left.\mathrm{m}^{2}\right)\end{array}$ & $\begin{array}{l}\text { average HRR }(\mathrm{kW} / \\
\left.\mathrm{m}^{2}\right)\end{array}$ & $\begin{array}{l}\text { THR }(\mathrm{MJ} / \\
\left.\mathrm{m}^{2}\right)\end{array}$ \\
\hline PP-0 & 1934.91 & 243.35 & 118.69 & PLA-0 & 870.11 & 183.70 & 67.65 \\
PP-3 & 635.61 & 155.86 & 97.79 & PLA-3 & 466.49 & 78.96 & 71.99 \\
PP-4 & 810.01 & 180.53 & 110.77 & PLA-4 & 667.66 & 87.96 & 63.52 \\
PP-7 & 338.71 & 55.27 & 85.72 & PLA-7 & 194.22 & 37.17 & 67.94 \\
\hline
\end{tabular}

the CP loading did not lead to the achievement of the $\mathrm{V}-0$ class in UL 94. Additionally, Fig. 4 represents the thickness of the char layer against the elapsed time for

(a)

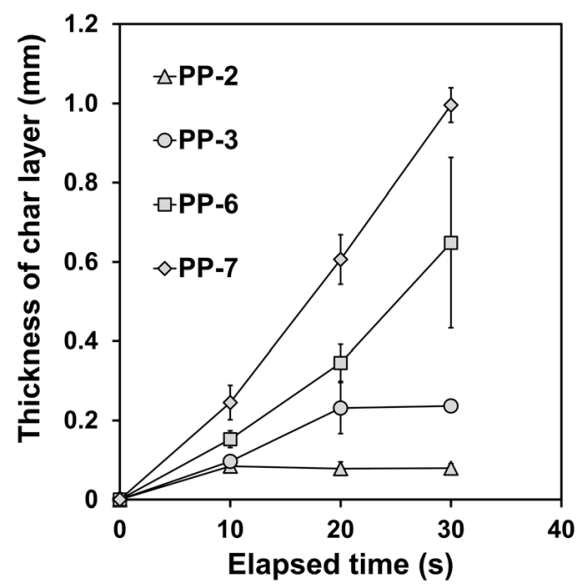

Fig. 4 Thickness of char layer against elapsed time after forced ignition for a PP-based composites and b PLA-based composites (The thickness of char layer was measured for 120 times samples with only CP added (PP-2, PP-3, PLA-2, PLA-3) and for samples with a combination of CP and APP added (PP-6, PP-7, PLA-6, PLA-7). The

(b)

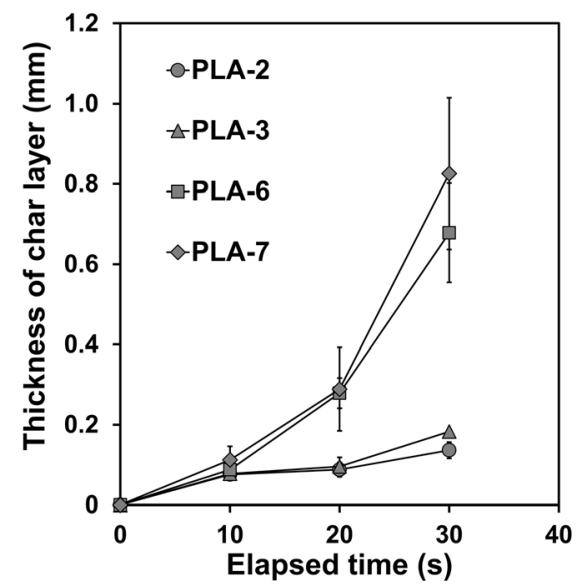

against each formulation. The average and standard deviation of char layer thickness were calculated from all measured data.) 
thickness of the char layer increased along with the elapsed time, and a higher amount of CP was found to lead to an increased char layer thickness. Therefore, $\mathrm{CP}$ has a positive effect on the fire retardancy of both matrices. However, the thickness of the char layer is not enough to achieve the $\mathrm{V}-0$ rating via only the addition of CP. Hence, dehydration of cellulose is assumed to be incomplete for the formation of char.

\section{Effect of APP addition}

The flammability of composites with only APP addition used as the fire retardant without CPs is discussed here. In the horizontal burning test, the PP composite (PP-4) burned until the end and the PLA composite (PLA-4) showed a self-extinguishing property via the addition of APP, as shown in Table 2. The addition of APP decreased the burning rate for PP as well. In the HRR curves from Fig. 3, the HRR for both composites with APP decreased compared with the neat polymer. Whereas, the pHRR of both composites containing APP was higher than composites containing the highest amount of CP. During combustion of composites containing APP, APP will decompose into phosphoric acid and ammonia (Zhao 2019; Dittrich et al. 2014; Maqsood and Seide 2019). Following the release of nonflammable gas such as water by dehydration, the ammonia will dilute the concentration of the combustible gas. In case of PLA, phosphoric acid can catalyze the dehydration reaction of the terminal alcohols of PLA, with, finally, a crosslinked or carbonized structure generated (Shi et al. 2017). Therefore, phosphorus containing flame retardant is more effective for polymers containing oxygen such as the PLA of polyester than PP.

\section{Effect of combination of APP and CP}

By incorporating APP and CP into both polymer matrices, dripping was not observed in the horizontal burning test. However, the difference in the flammability between PP composite and PLA composite for increased CP loading was confirmed. As shown in Table 2, PP composite showed a self-extinguishing property when $50 \mathrm{wt} \%$ of CPs were incorporated. On the other hand, the PLA composite showed a selfextinguishing property only when $10 \mathrm{wt} \%$ of CPs were added. This explained why the PLA itself showed better fire retardancy than PP and why APP reacted more effectively on PLA than PP. Additionally, the combination of CP and APP significantly increased the thickness of the char layer in comparison with the composites containing only $\mathrm{CP}$, as shown in Fig. 4. The phosphoric acid produced by the decomposition of APP effectively promotes the dehydration of the hydroxyl groups in cellulose (Seefeldt 2012; Kandola et al. 1996; Maqsood and Seide 2019), and, as a result, a thicker char layer is formed. This is the reason why both CP and APP addition improved the fire retardancy of both polymer composites. The increasing amount of CP promoted the reaction with APP effectively, which increased the thickness of the char layer.

In the vertical burning test, PP-7 (addition of 50 wt $\%$ CP and $10 \mathrm{wt} \%$ APP) showed a good selfextinguishing property without dripping. In the case of the PLA composites, up to 10 wt $\%$ of CP, PLA composite (PLA-5) showed dripping. Above $30 \mathrm{wt} \%$ of CP, PLA composites showed a good self-extinguishing property and a V-0 rating was achieved. From these results, the dehydration of $\mathrm{CP}$ by the incorporation of APP was found to effectively improve the fire retardancy of PP and PLA and in a vertical burning test too. This promotion of dehydration of cellulose produces a substantial amount of water and char during combustion. Consequently, the synergetic effect of water production as a nonflammable gas phase mechanism and char formation as a condensed phase mechanism essentially leads to achievement of the $\mathrm{V}-0$ rating. A small amount of $\mathrm{CP}$ showed dripping and melting phenomena. Therefore, enough $\mathrm{CP}$ is required to form the char layer while keeping the amount of APP small. From these analyses, we found that the synergetic effect of $\mathrm{CP}$ and APP enables one to provide excellent fire retardancy against both polymers.

\section{Thermal decomposition behavior}

From the previous section, production of water and char by dehydration of cellulose through incorporation of APP is important to achieve the $\mathrm{V}-0$ rating. Therefore, TGA was conducted due to determination of the dehydration temperature during combustion. The mass loss behavior and derivative thermogravimetry (DTG) curves for pure PP (PP-0), pure PLA (PLA-0) and CP are shown in Fig. 5a, b, respectively. In the $\mathrm{CP}$, the thermal decomposition 
(a)

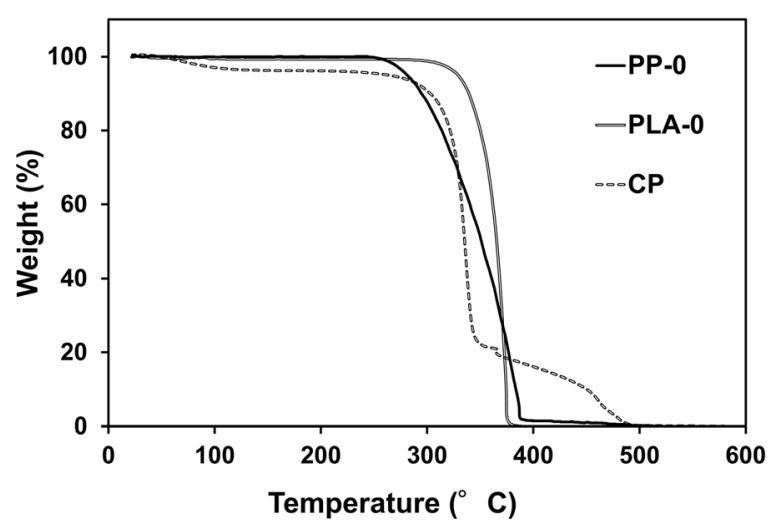

(b)

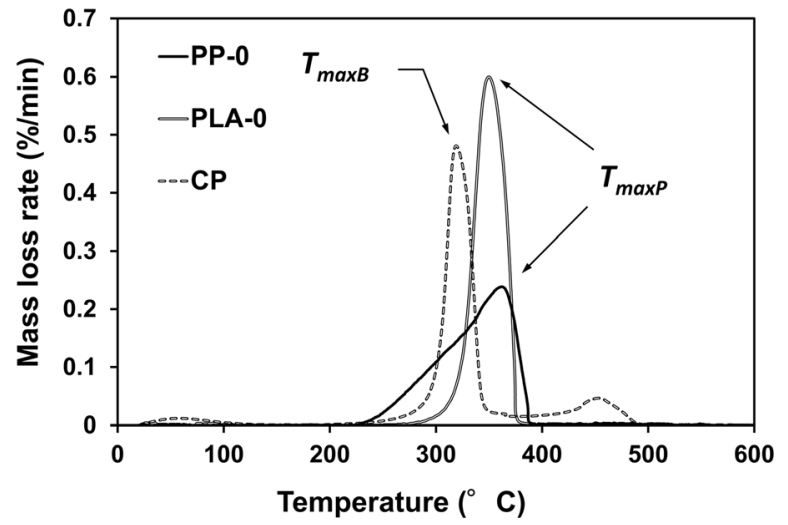

Fig. 5 a Mass loss curves and $\mathbf{b}$ mass loss rate curves for pure PP (PP-0), pure PLA (PLA-0) and CP. $\mathrm{T}_{\operatorname{maxB}}$ indicates the temperature at the maximum peak for $\mathrm{CP}$ and $\mathrm{T}_{\max }$ indicates the temperature at the maximum peak for neat polymers

behavior is divided into three steps. In the beginning, cellulose is slightly decomposed until $100{ }^{\circ} \mathrm{C}$ due to evaporation of absorbed moisture. After that, a second decomposition was observed from 220 to $350{ }^{\circ} \mathrm{C}$. Finally, decomposition from 350 to $480{ }^{\circ} \mathrm{C}$ was confirmed. The pyrolysis of cellulose can be divided into two steps at a threshold temperature of $300{ }^{\circ} \mathrm{C}$ (Kandola et al. 1996). At less than $300{ }^{\circ} \mathrm{C}$, cellulose reacts with atmospheric oxygen and forms oxycellulose, which on further heating decomposes with the evolution of water, carbon monoxide and carbon dioxide. Above $300{ }^{\circ} \mathrm{C}$, a gas, tar and char are produced.

When the thermal decomposition behavior is compared for pure PP, pure PLA and CP, the decomposition of $\mathrm{CP}$ is found to start at lower temperature $\left(220^{\circ} \mathrm{C}\right)$ than $\mathrm{PP}\left(270{ }^{\circ} \mathrm{C}\right)$ and PLA $\left(300{ }^{\circ} \mathrm{C}\right)$. This finding can also be explained from the temperature at the maximum peak in the DTG curve. Therefore, $\mathrm{CP}$ addition into the polymer matrix may exhibit a peak attributed to the dehydration reaction at lower temperature than the decomposition temperature of the polymer matrix. Here, the thermal decomposition behavior of PP composites and PLA composites through TGA is shown in Fig. 6a, b, respectively. However, the addition of only CP (PP-3, PLA-3) led to the exhibition of a two-staged decomposition behavior for both composites. The first decomposition temperature was not affected by $\mathrm{CP}$ addition and remained at almost the same decomposition temperature observed for the pure matrices although CP shows a lower decomposition temperature than the matrix. Finally, the carbonized residues did not remain at the end as well as for the neat matrices. Additionally, the addition of only APP (PP-4, PLA-4) also exhibited a two-stage decomposition: decomposition of polymer matrix and decomposition of carbon residues, and, finally, more residues were observed than for the system containing only CP.

Interestingly, in case of the combination of APP and CP (PP-6, PP-7, PLA-6, PLA-7), a three-step decomposition behavior was determined against both composites. The first decomposition occurring between 200 and $300{ }^{\circ} \mathrm{C}$ can be attributed to the dehydration of CP by interaction of APP. As discussed before, a nonflammable gas is generated here, and, then, char is formed with further heat above $300{ }^{\circ} \mathrm{C}$. The second decomposition corresponds to the decomposition of the matrix polymer. The third decomposition corresponds to the decomposition of the char, and the highest mass of carbonized residues can be obtained through all compositions. Thus, a combination of APP and CP can reduce the dehydration temperature against both composites. Furthermore, a higher $\mathrm{CP}$ amount led to a decrease in the temperature of the dehydration reaction of $\mathrm{CP}$. Therefore, the dehydration at lower temperature against the decomposition temperature of the neat polymer is effective to improve the fire retardancy of composites. 
(a)

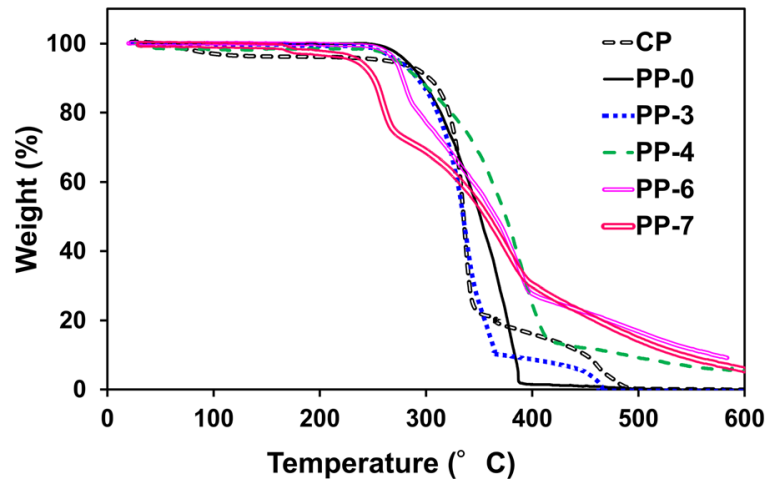

(b)

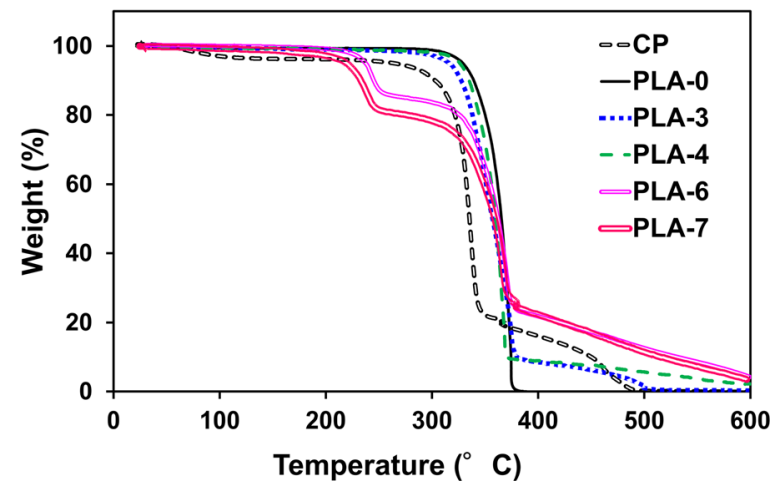

Fig. 6 Mass loss curves for a PP-based composites and b PLA-based composites

The parameters for achieving a $\mathrm{V}-0$ rating against the various polymers

From all the results, we proposed the hypothesis that the dehydration temperature of cellulose via the assistance of APP at lower temperature is important for achieving a V-0 rating. The TGA weight loss curves in Fig. 6 were converted to DTG curves, as shown in Fig. 7. From the explanation for the observed thermal decomposition behavior in the previous section, the combination of APP and CP shows three peaks. The first peak between 200 and $300{ }^{\circ} \mathrm{C}$ corresponds to the dehydration of cellulose, the second peak between 300 and $400{ }^{\circ} \mathrm{C}$ corresponds to the thermal oxidation of the polymer, and the third small peak between 400 and $500{ }^{\circ} \mathrm{C}$ corresponds to thermal decomposition of char residues. Here, the temperature

(a)

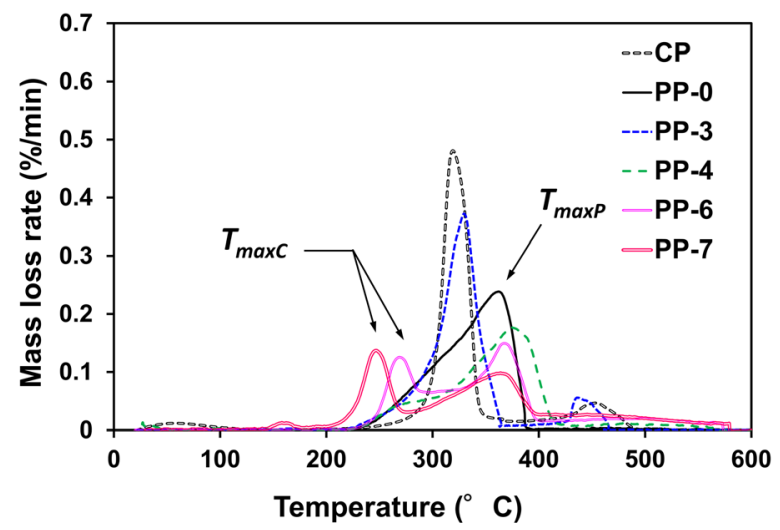

at the peak between 200 and $300{ }^{\circ} \mathrm{C}$ (dehydration temperature) in the DTG curve is denoted as $\mathrm{T}_{\operatorname{maxC}}$ for the composites incorporating $\mathrm{CP}$ and APP, the peak temperature for the neat polymer is denoted as $\mathrm{T}_{\max }$, and the second peak temperature for $\mathrm{CP}$ (dehydration temperature) is denoted as $\mathrm{T}_{\operatorname{maxB}}$. The $\mathrm{T}_{\max }, \mathrm{T}_{\max P}$ and $T_{\operatorname{maxB}}$ are represented in Figs. $5 \mathrm{~b}$ and 7 . Then, the temperature difference $\left(\Delta \mathrm{T}_{\max }\right)$ between the degradation temperature of the polymer $\left(\mathrm{T}_{\max }\right)$ and dehydration temperature $\left(\mathrm{T}_{\operatorname{maxC}}\right)$ of the composites can be given by Eq. 1:

$\Delta T_{\max }=T_{\max P}-T_{\max }$

The relationship between the thickness of the char layer at an elapsed time of $30 \mathrm{~s}$ and $\Delta \mathrm{T}_{\max }$ is plotted in Fig. 8. Furthermore, the relationship between the average HRR and $\Delta \mathrm{T}_{\max }$ is plotted in Fig. 9. From

Fig. 7 Mass loss rate curves for a PP-based composites and $\mathbf{b}$ PLA-based composites. $\mathrm{T}_{\operatorname{maxC}}$ indicates the peak temperature between 200 and $300{ }^{\circ} \mathrm{C}$ for the composites with $\mathrm{CP}$ and APP. $\mathrm{T}_{\operatorname{maxP}}$ indicates the maximum peak temperature for the neat polymers

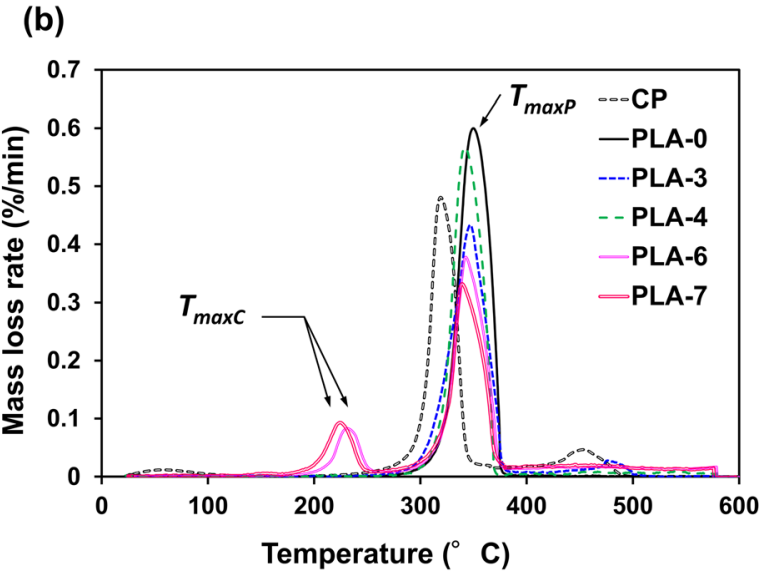




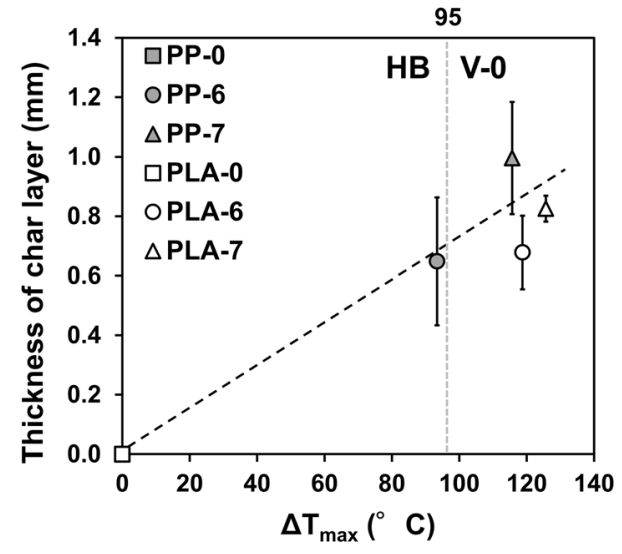

Fig. 8 Thickness of the char layer at an elapsed time of $30 \mathrm{~s}$ for PP-based composites and PLA-based composites against $\Delta \mathrm{T}_{\max }$ (i.e., $\mathrm{T}_{\operatorname{maxP}}-\mathrm{T}_{\operatorname{maxC}}$ )

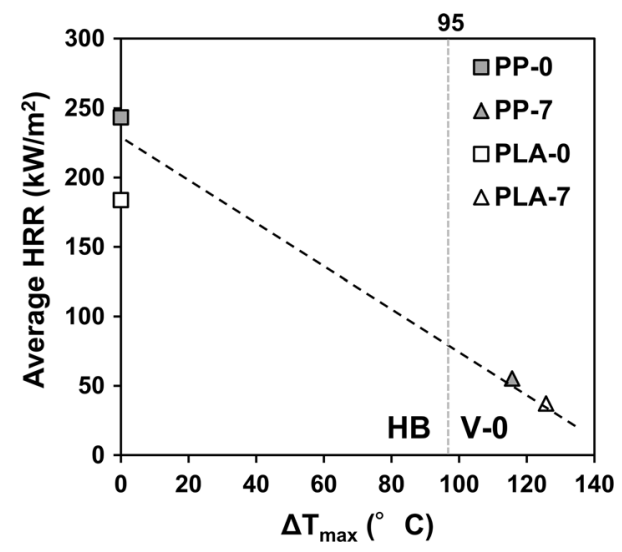

Fig. 9 Average heat release rate for PP-based composites and PLA-based composites against $\Delta \mathrm{T}_{\max }$ (i.e., $\mathrm{T}_{\operatorname{maxP}}-\mathrm{T}_{\max C}$ )

these figures, the linear correlation between the thickness of the char layer or average heat release rate and $\Delta \mathrm{T}_{\max }$ was confirmed. Furthermore, the thickness of the char layer increased, and the average HRR decreased with increasing $\Delta \mathrm{T}_{\max }$. Here, $\Delta \mathrm{T}_{\max }$ for PP-7, PLA-6 and PLA-7, which all exhibited a V-0 rating in Table 2, was determined to be $116^{\circ} \mathrm{C}$, $119{ }^{\circ} \mathrm{C}$ and $126{ }^{\circ} \mathrm{C}$, respectively. In case of the HB rating, $\Delta \mathrm{T}_{\max }$ was less than $95^{\circ} \mathrm{C}$. Therefore, it is necessary for $\Delta \mathrm{T}_{\max }$ to be at least above approximately $95{ }^{\circ} \mathrm{C}$ for achieving a V-0 rating. Here, the condition of $\Delta \mathrm{T}_{\max }$ for achieving a $\mathrm{V}-0$ rating is given by Eq. 2 :

$$
\left(\Delta T_{\max }\right)_{\min } \simeq 95^{\circ} \mathrm{C}
$$

In addition, the decomposition temperature of the polymer should be higher than the dehydration temperature of the cellulose itself. Therefore, the precondition should satisfy Eq. 3 as follows:

$T_{\max P}>T_{\max B}$

From the correlation in Figs. 8 and 9, the minimum thickness of the char layer and the average HRR for achieving a V-0 rating were determined to be above approximately $0.7 \mathrm{~mm}$ (for $30 \mathrm{~s}$ ) and below approximately $80 \mathrm{~kW} / \mathrm{m}^{2}$, respectively.

The validation of conditions for achieving a V-0 rating

Here, the suggested conditions for achieving a V-0 rating were validated by using a different polymer, polyoxymethylene (POM). The flammability of POM is quite high compared PP and PLA due to the very low LOI value of 15-16 (Harashina et al. 2006). Therefore, improvement of the fire retardancy for POM-based composites is a very challenging task. POM (Eupital, F20) was provided by the Mitsubishi EngineeringPlastics Corporation, Tokyo, Japan. Due to material limitation, wood flour was used as biofiller in this validation experiment. The wood flour $(\mathrm{BF} \alpha)$ was provided by K.K. Plaisir, Osaka, Japan. The particle size ranged from 50 to $150 \mu \mathrm{m}$. Here, we investigated the improvement in the fire retardancy realized by using a combination of APP and this BFa. The flammability test and TGA were conducted against POM composites. The formulations for the POM composites are listed in Table 4. The classification of the flammability for the UL 94 standard is also listed in the same table. Not only did the addition of only $\mathrm{BF} \alpha$ not show a V-0 rating in the flammability test but neither did the combination of $\mathrm{BF} \alpha$ and APP.

Here, we examined the reason for this from the TG and DTG curves obtained for POM composites according to the suggested condition for achieving a $\mathrm{V}-0$ rating. The TG and DTG curves for pure POM (POM-0), BF $\alpha$, POM composites with only $\mathrm{BF} \alpha$ (POM-1, POM-2) and POM composites with $\mathrm{BF} \alpha$ and APP (POM-3, POM-4) are shown in Fig. 10. The combination of APP and $\mathrm{BF} \alpha$ showed a peak that was attributed to the dehydration reaction of cellulose at temperature between 150 and $250{ }^{\circ} \mathrm{C}$, although the 
Table 4 The formulation of the POM composites and classification of the flammability test in UL 94

\begin{tabular}{lclll}
\hline Sample & POM $(\mathrm{wt} \%)$ & $\mathrm{BF} \alpha(\mathrm{wt} \%)$ & APP $(\mathrm{wt} \%)$ & Class based on UL94 \\
\hline POM-0 & 100 & 0 & 0 & HB \\
POM-1 & 70 & 30 & 0 & HB \\
POM-2 & 60 & 40 & 0 & HB \\
POM-3 & 64 & 27 & 9 & HB \\
POM-4 & 55 & 36 & 9 & HB \\
\hline
\end{tabular}

(a)

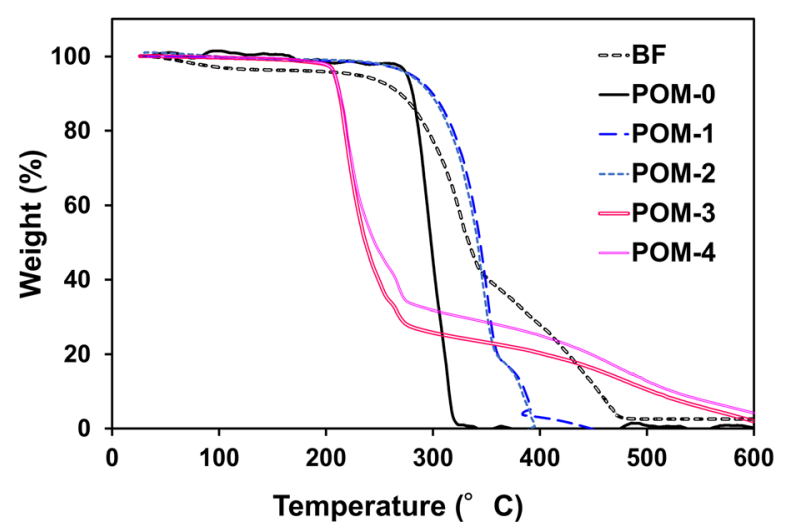

Fig. 10 a Mass loss curves and $\mathbf{b}$ mass loss rate curves for $B F \boldsymbol{\alpha}$ (wood flour), pure POM, POM composites with BF $\alpha$ and POM composites with $\mathrm{BF}$ and $\mathrm{APP} . \mathrm{T}_{\operatorname{maxC}}$ indicates the peak

addition of only BF $\alpha$ did not show a peak. This is the same phenomena observed for the PP composites and PLA composites. The decomposition temperature $\left(\mathrm{T}_{\operatorname{maxP}}\right)$ for $\mathrm{POM}$ was found be approximately $290{ }^{\circ} \mathrm{C}$ and the dehydration temperature $\left(\mathrm{T}_{\operatorname{maxB}}\right)$ for $\mathrm{BF} \alpha$ was approximately $300{ }^{\circ} \mathrm{C}$. Each peak temperature is shown in Fig. 10. The decomposition temperature for POM was smaller than the dehydration temperature of $\mathrm{BF} \alpha$, and hence, Eq. 3 was not satisfied in this composition. From the thermal decomposition behavior observed in the DTG curves, $\Delta \mathrm{T}_{\max }$ was found to be approximately $73{ }^{\circ} \mathrm{C}$ against POM-3 and POM-4, and Eq. 2 was not satisfied. Hence, in case of POM-based composites, a V-0 rating could not be achieved. We proved that the precondition of Eq. 3 is important for obtaining the synergetic effect of cellulose and APP through this validation experiment. Through these tests, we discovered that both conditions of Eqs. 2 and 3 are necessary to providing excellent fire retardancy against composites incorporating biofiller and APP.

\section{(b)}

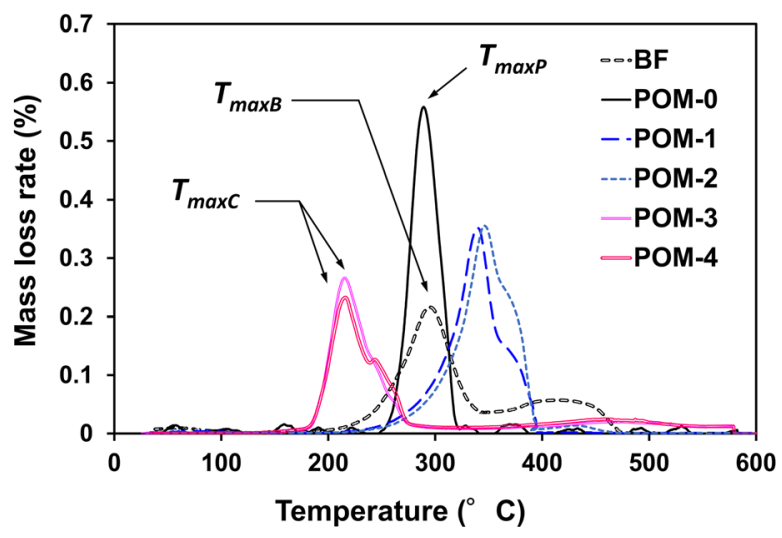

temperature between 200 and $300{ }^{\circ} \mathrm{C}$ for composites with $\mathrm{BF} \alpha$ and $\mathrm{APP} . \mathrm{T}_{\max }$ indicates the maximum peak temperature for neat POM

\section{Conclusions}

The motivation of this study was to (1) reveal the mechanism for fire retardancy of composites containing a combination of biofillers and APP regardless of the kind of polymer used and (2) determine the parameters required for achieving a V-0 rating in UL 94. In this study, PP, PLA and POM were used as a polymer matrix, and various amounts of cellulose and APP were incorporated. Through a flammability test, cone calorimetry test, TGA and observation of the thickness of the char layer formed, we discovered the conditions necessary for achieving a V-0 rating to be as follows:

1. The dehydration of cellulose by assistance of APP in composites should start at approximately $95^{\circ} \mathrm{C}$ less than the degradation temperature of the neat polymer for generation of enough nonflammable gas and char layer.

2. The dehydration temperature of the biofiller itself must be less than the degradation temperature of the neat polymer. 
By satisfaction of the above conditions, incorporation of $50 \mathrm{wt} \%$ loading of cellulose in PP and $30 \mathrm{wt} \%$ loading of cellulose in PLA enabled one to achieve a $\mathrm{V}-0$ rating with $10 \mathrm{wt} \%$ loading of APP. The reason for this was that the APP addition reduced the dehydration temperature of the biofiller, and consequently a substantial amount of nonflammable gas such as water and a sufficient char layer was generated before the degradation of the polymer. Thus, the synergetic effect between dilution of flammable gas, endothermic reaction by generated water and the insulation of oxygen by the char layer sufficiently acted on improving the fire retardancy. From these new findings for achieving a V-0 rating via the use of biofillers and APP, these conditions will provide a new solution for material selection considerations and optimizing formulations without trial and error before compounding materials.

Open Access This article is licensed under a Creative Commons Attribution 4.0 International License, which permits use, sharing, adaptation, distribution and reproduction in any medium or format, as long as you give appropriate credit to the original author(s) and the source, provide a link to the Creative Commons licence, and indicate if changes were made. The images or other third party material in this article are included in the article's Creative Commons licence, unless indicated otherwise in a credit line to the material. If material is not included in the article's Creative Commons licence and your intended use is not permitted by statutory regulation or exceeds the permitted use, you will need to obtain permission directly from the copyright holder. To view a copy of this licence, visit http://creativecommons.org/licenses/by/4.0/.

\section{References}

Ahmed L, Zhang B, Hatanaka LC, Mannan MS (2018) Application of polymer nanocomposites in the flame retardancy study. J Loss Prev Process Ind 55:381-391. https://doi.org/ 10.1016/j.jlp.2018.07.005

Arao Y, Nakamura S, Tomita Y, Takakuwa K, Umemura T, Tanaka T (2014) Improvement on fire retardancy of wood flour/polypropylene composites using various fire retardants. Polym Degrad Stab 100:79-85. https://doi.org/10. 1016/j.polymdegradstab.2013.12.022

Bajwa DS, Rehovsky C, Shojaeiarani J, Stark N, Bajwa S, Dietenberger MA (2019) Functionalized cellulose nanocrystals: a potential fire retardant for polymer composites. Polymers 11:1361. https://doi.org/10.3390/ polym 11081361

Botlhoko OJ, Ramontja J, Ray SS (2017) Thermally shocked graphene oxide-containing biocomposite for thermal management applications. RSC Adv 7:33751-33756. https://doi.org/10.1039/C7RA05421A
Bourbigot S, Fontaine G (2010) Flame retardancy of polylactide: an overview. Polym Chem 1:1413-1422. https://doi. org/10.1039/C0PY00106F

Castro-Aguirre E, Iñiguez-Franco F, Samsudin H, Fang X, Auras R (2016) Poly(lactic acid)-mass production, processing, industrial applications, and end of life. Adv Drug Deliv Rev 107:333-366. https://doi.org/10.1016/j.addr. 2016.03.010

Castrovinci A, Camino G (2007) Fire-retardant mechanisms in polymer nano-composite materials. In: Duquesne $\mathrm{S}$, Magniez C, Camino G (eds) Multifunctional barriers for flexible structure. Springer, Berlin, pp 87-108

Chow WS, Teoh EL, Karger-Kocsis J (2018) Flame retarded poly(lactic acid): a review. Express Polym Lett 12:396-417. https://doi.org/10.3144/expresspolymlett. 2018.34

Costes L, Laoutid F, Aguedo M, Richel A, Brohez S, Delvosalle C, Dubois P (2016a) Phosphorus and nitrogen derivatization as efficient route for improvement of lignin flame retardant action in PLA. Eur Polym J 84:652-667. https:// doi.org/10.1016/j.eurpolymj.2016.10.003

Costes L, Laoutid F, Khelifa F, Rose G, Brohez S, Delvosalle C, Dubois P (2016b) Cellulose/phosphorus combinations for sustainable fire retarded polylactide. Eur Polym J 74:218-228. https://doi.org/10.1016/j.eurpolymj.2015.11. 030

Dittrich B, Wartig KA, Mülhaupt R, Schartel B (2014) Flameretardancy properties of intumescent ammonium poly(phosphate) and mineral filler magnesium hydroxide in combination with graphene. Polymers 6:2875-2895. https://doi.org/10.3390/polym6112875

Fox DM, Novy M, Brown K, Zammarano M, Harris RH, Murariu M, McCarthy ED, Seppala JE, Gilman JW (2014) Flame retarded poly(lactic acid) using POSS-modified cellulose. 2. Effects of intumescing flame retardant formulations on polymer degradation and composite physical properties. Polym Degrad Stab 106:54-62. https://doi.org/ 10.1016/j.polymdegradstab.2014.01.007

Guo Y, He S, Zuo X, Xue Y, Chen Z, Chang CC, Weil E, Rafailovich M (2017) Incorporation of cellulose with adsorbed phosphates into poly (lactic acid) for enhanced mechanical and flame retardant properties. Polym Degrad Stab 144:24-32. https://doi.org/10.1016/j. polymdegradstab.2017.08.004

Hanna AA, Nour MA, Souaya ER, sherief MA, Abdelmoaty AS (2018) Studies on the flammability of polypropylene/ammonium polyphosphate and montmorillonite by using the cone calorimeter test. Open Chem 16:108-115. https://doi. org/10.1515/chem-2018-0013

Harashina H, Tajima Y, Itoh T (2006) Synergistic effect of red phosphorus, novolac and melamine ternary combination on flame retardancy of poly(oxymethylene). Polym Degrad Stab 91:1996-2002. https://doi.org/10.1016/j. polymdegradstab.2006.02.010

Hurtado PL, Rouilly A, Vandenbossche V, Raynaud C (2016) A review on the properties of cellulose fibre insulation. Build Environ 96:170-177. https://doi.org/10.1016/j.buildenv. 2015.09.031

Jiang D, Pan M, Cai X, Zhao Y (2018) Flame retardancy of rice straw-polyethylene composites affected by in situ polymerization of ammonium polyphosphate/silica. Compos 
Part A 109:1-9. https://doi.org/10.1016/j.compositesa. 2018.02.023

Kandola BK, Horrocks AR, Price D, Coleman GV (1996) Flame-retardant treatments of cellulose and their influence on the mechanism of cellulose pyrolysis. J Macromol Sci C 36:721-794. https://doi.org/10.1080/15321799608014859

Kozłowski R, Władyka-Przybylak M (2008) Flammability and fire resistance of composites reinforced by natural fibers. Polym Adv Technol 19:446-453. https://doi.org/10.1002/ pat. 1135

Li B, He J (2004) Investigation of mechanical property, flame retardancy and thermal degradation of LLDPE-wood-fibre composites. Polym Degrad Stab 83:241-246. https://doi. org/10.1016/S0141-3910(03)00268-4

Liao F, Ju Y, Dai X, Cao Y, Li J, Wang X (2015) A novel efficient polymeric flame retardant for poly (lactic acid) (PLA): synthesis and its effects on flame retardancy and crystallization of PLA. Polym Degrad Stab 120:251-261. https://doi.org/10.1016/j.polymdegradstab.2015.07.012

Maqsood M, Seide G (2019) Investigation of the flammability and thermal stability of halogen-free intumescent system in biopolymer composites containing biobased carbonization agent and mechanism of their char formation. Polymers 11:48. https://doi.org/10.3390/polym 11010048

Matkó S, Toldy A, Keszei S, Anna P, Bertalan G, Marosi G (2005) Flame retardancy of biodegradable polymers and biocomposites. Polym Degrad Stab 88:138-145. https:// doi.org/10.1016/j.polymdegradstab.2004.02.023
Salmeia KA, Jovic M, Ragaisiene A, Rukuiziene Z, Milasius R, Mikucioniene D, Gaan S (2016) Flammability of cellulosebased fibers and the effect of structure of phosphorus compounds on their flame retardancy. Polymers 8:293. https://doi.org/10.3390/polym8080293

Seefeldt H (2012) Flame retardancy of wood-plastic composites. Dissertation, Technicsl University of Berlin

Shi X, Liao F, Ju Y, Dai X, Cao Y, Li J, Wang X (2017) Improving the flame retardance and melt dripping of poly(lactic acid) with a novel polymeric flame retardant of high thermal stability. Fire Mater 41:362-374. https://doi. org/10.1002/fam.2389

Stark NM, White RH, Mueller SA, Osswald TA (2010) Evaluation of various fire retardants for use in wood flourpolyethylene composites. Polym Degrad Stab 95:1903-1910. https://doi.org/10.1016/j.polymdegradstab. 2010.04.014

UL 94 (2013) Tests for flammability of plastic materials for parts in devices and appliances. Underwriters Laboratories, United States of America

Zhao P (2019) Development and investigation of bio-based environmentally friendly fire retardant PLA composites. Dissertation, Chemnitz University of Technology

Publisher's note Springer Nature remains neutral with regard to jurisdictional claims in published maps and institutional affiliations. 